\title{
EFICIÊNCIA DE EXTRATORES DE POTÁSSIO DISPONÍVEL EM SOLOS DO ESTADO DA PARAÍBA COM GRAUS DE DESENVOLVIMENTO PEDOGENÉTICO DIFERENTES ${ }^{(1)}$
}

\author{
Jailma dos Santos de Medeiros ${ }^{(2)}$, Fábio Henrique Tavares de Oliveira ${ }^{(3)}$, \\ Jandeilson Alves de Arruda ${ }^{(4)}$, Montesquieu da Silva Vieira ${ }^{(2)}$ \& Maurício Paulo \\ Ferreira Fontes ${ }^{(5)}$
}

\begin{abstract}
RESUMO
A disponibilidade de potássio (K) às plantas depende dos teores das formas de $\mathrm{K}$ nos solos (K não trocável, $\mathrm{K}$ trocável e $\mathrm{K}$ solúvel), os quais variam com o grau de desenvolvimento pedogenético dos solos. O objetivo deste trabalho foi avaliar a disponibilidade de $\mathrm{K}$ em solos com graus de desenvolvimento pedogenético diferentes, por meio da extração de $\mathrm{K}$ dos solos com diferentes extratores e com plantas de milho. Foram coletadas amostras da camada de 0 a $30 \mathrm{~cm}$ de 12 solos representativos do Estado da Paraíba, sendo seis mais desenvolvidos e seis menos desenvolvidos. Em três repetições de todos os 12 solos, foram aplicadas cinco doses de $\mathrm{K}\left(0,50,100,200\right.$ e $\left.300 \mathrm{mg} \mathrm{dm}^{-3}\right)$, na forma de $\mathrm{KCl}$ p.a. em solução, e incubadas durante 21 dias. Após esse período, uma subamostra de cada solo foi retirada para determinação dos teores de K disponível pelos extratores Mehlich-1, Mehlich-3 e resina de troca iônica. Em seguida, os solos foram cultivados com milho em casa de vegetação durante 30 dias, e depois avaliaram-se a produção de matéria seca e o teor de K na planta. Os extratores Mehlich-1, Mehlich-3 e a resina de troca iônica extraíram teores semelhantes de $\mathrm{K}$ nos solos mais desenvolvidos. No grupo de solos menos desenvolvidos, os extratores Mehlich-1 e Mehlich-3 extraíram teores semelhantes de K, mas bem maiores que os de K extraídos pela resina de troca iônica, especialmente naqueles com maior teor de argila e maior proporção de minerais do tipo 2:1. Ao contrário dos extratores Mehlich-1 e Mehlich-3, nos solos menos desenvolvidos a resina de troca iônica não apresentou boa correlação com o teor de K trocável. Neste grupo de solos, o extrator Mehlich-1
\end{abstract}

\footnotetext{
(1) Parte da Dissertação de Mestrado do primeiro autor apresentada ao Programa de Pós-Graduação em Manejo de Solo e Água da Universidade Federal da Paraíba - UFPB. Trabalho financiado pelo CNPq. Recebido para publicação em dezembro de 2008 e aprovado em outubro de 2009.

(2) Mestre em Manejo de Solo e Água, Departamento de Solos e Engenharia Rural, Universidade Federal da Paraíba - CCA/ UFPB. CEP 58397-000 Areia (PB). E-mail: jailmagronomia@hotmail.com

(3) Professor Adjunto do Departamento de Ciências Ambientais e Tecnológicas, Universidade Federal Rural do Semi-Árido. CEP 59625-900 Mossoró (RN). Bolsista do CNPq. E-mail: fabio@ufersa.edu.br

(4) Pós-Graduando em Solos e Nutrição de Plantas da Universidade Federal de Viçosa - UFV. CEP 36571-000 Viçosa (MG). Email: jandeilson_agro@hotmail.com

${ }^{(5)}$ Professor Titular do Departamento de Solos, UFV. E-mail: mpfontes@ufv.br
} 
foi o que mostrou melhor correlação com o conteúdo de K na planta. Na maioria dos solos, a produção de matéria seca da planta não aumentou com o aumento das doses de K, porém em todos eles houve aumento do teor de $\mathrm{K}$ na planta em resposta à adubação potássica.

Termos de indexação: extratores, disponibilidade de potássio disponível, formas de potássio, semiárido.

\title{
SUMMARY: EFFICIENCY OF AVAILABLE POTASSIUM EXTRACTANTS IN SOILS OF PARAIBA STATE WITH DIFFERENT DEGREES OF PEDOGENETICDEVELOPMENT
}

\begin{abstract}
Potassium availability for plants depends on the contents of the $K$ forms present in the soils (non exchangeable, exchangeable and soluble K), which vary according to the degree of pedogenetic development of soils. The objective of this study was to evaluate Kavailability in soils with different degrees of pedogenetic development, based on the extraction of $K$ from the soils with different extractants and with corn plants. Samples of the surface layer $(0-30 \mathrm{~cm})$ were collected from 12 representative soils in the state of Paraiba, of which six were more and six less developed. To the three replications of all 12 soils, five $K$ doses $(0 ; 50 ; 100 ; 200$, and $300 \mathrm{mg} \mathrm{dm}^{-3}$ ) were applied in the form of $\mathrm{KCl}$ in solution and incubated for 21 days. Following, a sub-sample of $0.2 \mathrm{dm}^{-3}$ of each soil was taken to determine the content of available $K$ by the extractors Mehlich-1, Mehlich-3 and ion exchange resin. Then, corn was grown on the soils in a greenhouse for 30 days and the dry matter production and K plant content evaluated. The extractants Mehlich-1, Mehlich-3 and ion exchange resin extracted similar Kamounts in the more developed soils. In the group of less developed soils, the extractants Mehlich-1 and Mehlich-3 extracted not very different $K$ amounts, but much greater amounts than by ion exchange resin, especially in the soils with higher clay content and a larger proportion of 2:1 minerals. Unlike the extractants Mehlich-1 and Mehlich-3, ion exchange resin was not wellrelated with the exchangeable K content in the less developed soils. In this soil group, Mehlich-1 correlated best with the plant K content. In most soils the dry matter production of the plant did not increase with increasing $K$ doses, but in all soils the $K$ plant content increased in response to K fertilization.
\end{abstract}

Index terms: extractants, availability potassium, potassium forms, semi-arid.

\section{INTRODUÇÃO}

A avaliação da disponibilidade de potássio (K) nos solos pelos diversos métodos de extração tem apresentado resultados insatisfatórios em razão da impossibilidade de todas as formas desse elemento (K solúvel, K trocável e K não trocável) serem avaliadas em laboratórios de rotina com boa exatidão e pelo fato de, a rigor, não existir limite nítido entre essas formas. Vários trabalhos demonstraram que em muitos solos pobres em K trocável as culturas não responderam à adubação potássica, levando à conclusão de que o K trocável não é a única fonte de $\mathrm{K}$ para as plantas e que é necessário avaliar a contribuição de outras formas desse elemento para a nutrição das culturas (Nachtigall \& Vall, 1991a,b; Rosolem et al., 1993; Melo et al., 1995; Castilhos \& Meurer, 2002).

Vários são os métodos disponíveis para a análise de $\mathrm{K}$ em solos, e muitos dos extratores utilizados nas análises de rotina são multielementares, em geral desenvolvidos para outros nutrientes, sendo usados para $\mathrm{K}$ em razão da facilidade de extração do $\mathrm{K}$ trocável. O teor de K extraído do solo é dependente da natureza de ação do extrator; entre muitos extratores, a solução de acetato de amônio $1 \mathrm{~mol} \mathrm{~L}^{-1}$ a pH 7,0 é uma das mais utilizadas para extrair o $\mathrm{K}$ trocável, por envolver o mecanismo de troca de cátions entre $o$ $\mathrm{K}^{+}$e o $\mathrm{NH}_{4}^{+}$(Nachtigall \& Raij, 2005). Segundo Raij (1991), para os solos brasileiros, processos de extração que utilizam ácidos diluídos e a resina trocadora de íns fornecem resultados semelhantes aos do acetato de amônio, permitindo que os extratores usados para fósforo $(\mathrm{P})$ em laboratórios de rotina também o sejam para K. Contudo, essa semelhança entre os extratores ainda não foi confirmada para solos do semiárido brasileiro, especialmente para aqueles com maior teor de argila e maior proporção de minerais do tipo 2:1.

As formas imediatamente disponíveis de $\mathrm{K}$ para as plantas são o K trocável e o K em solução, sendo estas as determinadas na análise química do solo em 
laboratórios de rotina (Mielniczuk, 1980). O K não trocável do solo é calculado subtraindo-se do K extraído com $\mathrm{HNO}_{3} 1 \mathrm{~mol} \mathrm{~L}^{-1}$ fervente o K trocável extraído com acetato de amônio $1 \mathrm{~mol} \mathrm{~L}^{-1}$ a pH 7,0 (Helmke \& Sparks, 1996). O K disponível do solo pode ser definido como o teor de K extraído do solo por um extrator, que se correlaciona estreitamente com a quantidade de $\mathrm{K}$ acumulada na planta ou com a produção de matéria seca dessa planta (Alvarez V., 1996). No Brasil, o Mehlich-1 (Silva et al., 1998) e a resina de troca iônica (Raij et al., 2001) são os extratores de K disponível utilizados nos laboratórios de rotina de análises químicas de solos.

Os quatro laboratórios de rotina de análises de solos existentes no Estado da Paraíba utilizam unicamente o extrator Mehlich-1 para avaliar a disponibilidade de $\mathrm{K}$, independentemente do tipo de solo. No Estado da Paraíba ocorre grande variação de solos, encontrandose desde solos jovens, como os Neossolos Litólicos e os Luvissolos, até solos bastante desenvolvidos, como os Latossolos e Argissolos (Brasil, 1972). Assim, é de se esperar que o extrator Mehlich-1 não seja eficiente para quantificar corretamente toda a reserva de $\mathrm{K}$ disponível para as plantas em todos os solos do Estado, principalmente naqueles mais argilosos e menos desenvolvidos, que possivelmente apresentam maiores teores de $\mathrm{K}$ não-trocável e são de grande ocorrência no Estado.

Neste trabalho, objetivou-se determinar o teor de K disponível pelos extratores Mehlich-1, Mehlich-3 e resina de troca iônica em solos representativos do Estado da Paraíba, bem como relacionar esses teores de K extraídos com as características químicas, físicas e mineralógicas desses solos e com o acúmulo de $\mathrm{K}$ em plantas de milho.

\section{MATERIAL E MÉTODOS}

Foram coletadas amostras da camada de 0 a $30 \mathrm{~cm}$ de 12 solos representativos do Estado da Paraíba (Oliveira et al., 2006), sendo seis mais desenvolvidos pedogeneticamente $(\mathrm{Ki} \leq 2,46)$ e seis menos desenvolvidos (Ki > 2,46), representando 11 subordens do Sistema Brasileiro de Classificação de Solos. Dentro de cada grupo de seis solos, os mesmos apresentam ampla variação de características morfológicas, químicas, físicas e mineralógicas. As amostras desses solos foram secas ao ar e passadas em peneira de $4 \mathrm{~mm}$ de malha e devidamente homogeneizadas, das quais foram retiradas subamostras de $10 \mathrm{dm}^{3}$ para serem passadas em peneira de $2 \mathrm{~mm}$ de malha e depois caracterizadas química, física e mineralogicamente (Quadro 1), conforme Embrapa (1997). O P remanescente (P-rem) foi determinado após agitação das amostras de solo durante 5 min com solução de $\mathrm{CaCl}_{2} 10 \mathrm{mmol} \mathrm{L}^{-1}$ contendo $60 \mathrm{mg} \mathrm{L}^{-1}$ de $\mathrm{P}$, deixadas em repouso para decantação durante $16 \mathrm{~h}$ (Alvarez V. et al., 2000).
A necessidade de calagem dos solos foi calculada pelo método da neutralização do $\mathrm{Al}^{3+} \mathrm{e}$ elevação dos teores de $\mathrm{Ca}^{2+}+\mathrm{Mg}^{2+}$ (Ribeiro et al., 1999) e pelo método da saturação por bases; todavia, para a realização da calagem, levou-se em consideração a média aritmética dos valores de necessidade de calagem estimados por esses dois métodos. Apenas os solos PA, PAC, PVA e PVd receberam calagem, o que foi feito aplicando-se uma mistura de $\mathrm{CaCO}_{3}$ (p.a.) e de $\mathrm{MgCO}_{3}$ (p.a.) numa relação molar 4:1 e incubando os solos por duas semanas com quantidade de água correspondente a $50 \%$ da porosidade total de cada solo. Após a correção da acidez desses solos, em três repetições, foram aplicadas as mesmas doses de $\mathrm{K}(0$, $50,100,200$ e $300 \mathrm{mg} \mathrm{dm}^{-3}$ ), na forma de $\mathrm{KCl}$ p.a. em solução, incubando-os durante 21 dias com quantidade de água correspondente a $50 \%$ da porosidade total de cada solo. Esses dois períodos de incubação foram estabelecidos com as amostras de solos $\left(3,2 \mathrm{dm}^{3}\right)$ dentro de vasos plásticos em casa de vegetação.

Após cada período de incubação, as amostras de todos os solos foram secas ao ar, destorroadas, passadas em peneira de $4 \mathrm{~mm}$ e devolvidas aos vasos. Em seguida, uma subamostra de $0,2 \mathrm{dm}^{3}$ do solo de cada vaso foi retirada e passada em peneira de $2 \mathrm{~mm}$ de malha para determinação dos teores de $\mathrm{K}$ recuperados pela resina de troca iônica mista (Raij et al., 2001) e pelos extratores químicos Mehlich-1, Mehlich-3 e acetato de amônio $1 \mathrm{~mol} \mathrm{~L}^{-1} \mathrm{a} \mathrm{pH}$ 7,0 (K trocável), utilizando-se a relação solo:solução $(\mathrm{m} / \mathrm{v})$ de 1:10 e tempo de agitação de 5 min (Helmke \& Sparks, 1996). Para cada solo e para todas as formas de K, os teores de $\mathrm{K}$ no solo em $\mathrm{mg} \mathrm{kg}^{-1}$ foram multiplicados pela densidade do solo (Quadro 1), a fim de obter os resultados em $\mathrm{mg} \mathrm{dm}^{-3}$. A decisão de expressar a maioria das unidades com base no volume de solo foi norteada pelo princípio de que as raízes das plantas exploram um volume de solo e não uma massa de solo. Além disso, cumpre observar que os solos foram colocados nos vasos com base nos mesmos valores de densidade do solo, ou seja, foi calculada a massa de solo correspondente ao volume de solo $\left(3 \mathrm{dm}^{3}\right)$ contido no vaso e a densidade dele. Idêntico procedimento foi aplicado para a adição das doses de $\mathrm{K}$ aos solos.

O volume de solo restante $\left(3,0 \mathrm{dm}^{3}\right)$ recebeu adubação com macro e micronutrientes (exceto K). No plantio, as amostras de solos dos vasos foram adubadas com $20 \mathrm{mg} \mathrm{dm}^{-3}$ de $\mathrm{N}$ na forma de $\mathrm{NH}_{4} \mathrm{H}_{2} \mathrm{PO}_{4}, 80 \mathrm{mg} \mathrm{dm}{ }^{-3}$ de $\mathrm{S}\left[\left(\mathrm{NH}_{4}\right)_{2} \mathrm{SO}_{4}\right], 0,5 \mathrm{mg} \mathrm{dm}^{-3}$ de $\mathrm{B}\left(\mathrm{H}_{3} \mathrm{BO}_{3}\right), 2,2 \mathrm{mg} \mathrm{dm}^{-3}$ de $\mathrm{Cu}\left(\mathrm{CuSO}_{4} .5 \mathrm{H}_{2} \mathrm{O}\right)$, $8 \mathrm{mg} \mathrm{dm}{ }^{-3}$ de $\mathrm{Fe}\left(\mathrm{FeCl}_{3} \cdot 6 \mathrm{H}_{2} \mathrm{O}\right.$ dissolvido em solução diluída de EDTA), $6 \mathrm{mg} \mathrm{dm}^{-3}$ de $\mathrm{Zn}\left(\mathrm{ZnSO}_{4} \cdot 7 \mathrm{H}_{2} \mathrm{O}\right)$ e $0,15 \mathrm{mg} \mathrm{dm}^{-3}$ de Mo $\left[\left(\mathrm{NH}_{4}\right)_{6} \mathrm{Mo}_{7} \mathrm{O}_{24} \cdot 4 \mathrm{H}_{2} \mathrm{O}\right]$. Em cobertura, foram aplicados $130 \mathrm{mg} \mathrm{dm}^{-3}$ de N $\left[\left(\mathrm{NH}_{4}\right)_{2} \mathrm{SO}_{4}\right]$, divididos em três aplicações. As doses de $\mathrm{P}$ foram escolhidas com base no valor de $\mathrm{P}$ remanescente (Alvarez V. et al., 2000) e foram aplicadas em $100 \%$ do volume de solo do vaso no plantio. Nos solos PA, LA, PVA, TX, RY, RL e SX 
Quadro 1. Características químicas, físicas e mineralógicas de 12 solos representativos do Estado da Paraíba ${ }^{(1)}$

\begin{tabular}{|c|c|c|c|c|c|c|c|c|c|c|c|c|}
\hline \multirow{3}{*}{ Característica } & \multicolumn{10}{|c|}{ Solo $^{(2)}$} & & \\
\hline & \multicolumn{6}{|c|}{ Mais desenvolvido } & \multicolumn{6}{|c|}{ Menos desenvolvido } \\
\hline & PA & PAC & PVe & PVA & LA & PVd & RR & $\mathbf{R L}$ & TX & SX & RY & VX \\
\hline $\mathrm{pH}\left(\mathrm{H}_{2} \mathrm{O}\right)$ & 5,9 & 4,4 & 6,3 & 5,5 & 5,9 & 5,0 & 7,0 & 6,2 & 6,2 & 7,2 & 7,3 & 8,4 \\
\hline $\mathrm{CO}\left(\right.$ dag kg $\left.{ }^{-1}\right)$ & 0,35 & 1,07 & 0,90 & 1,07 & 0,59 & 0,80 & 0,34 & 0,38 & 0,76 & 0,43 & 0,89 & 0,37 \\
\hline $\mathrm{P}\left(\mathrm{mg} \mathrm{dm} \mathrm{dm}^{-3}\right)$ & 1,52 & 3,59 & 6,80 & 2,63 & 11,42 & 2,32 & 24,07 & 4,31 & 4,35 & 21,58 & 144,33 & 19,77 \\
\hline K-Mehlich-1 $\left(\mathrm{cmol}_{\mathrm{c}} \mathrm{dm}^{-3}\right)$ & 0,04 & 0,10 & 0,39 & 0,24 & 0,18 & 0,19 & 0,18 & 0,19 & 0,64 & 0,21 & 0,60 & 0,69 \\
\hline $\mathrm{K}$ não-trocável ${ }^{(3)}\left(\mathrm{mg} \mathrm{dm}^{-3}\right)$ & 6,4 & 12,2 & 370,4 & 139,9 & 23,2 & 100,4 & 210,6 & 642,6 & 853,1 & $2.052,3$ & $2.728,9$ & $1.128,2$ \\
\hline $\mathrm{K}$ trocável $^{(3)}\left(\mathrm{mg} \mathrm{dm}^{-3}\right)$ & 25,0 & 42,8 & 238,1 & 109,7 & 92,4 & 95,4 & 83,6 & 112,0 & 408,7 & 100,7 & 304,5 & 658,2 \\
\hline $\mathrm{K}$ solúvel-CaCl${ }_{2}^{(3)}\left(\mathrm{mg} \mathrm{dm}^{-3}\right)$ & 19,2 & 32,9 & 103,2 & 67,3 & 50,3 & 49,6 & 49,7 & 36,4 & 170,0 & 38,4 & 114,8 & 83,2 \\
\hline K solúvel-água ${ }^{(3)}\left(\mathrm{mg} \mathrm{dm}^{-3}\right)$ & 19,4 & 26,6 & 54,9 & 36,0 & 39,7 & 37,1 & 36,6 & 24,8 & 67,1 & 18,4 & 51,1 & 17,8 \\
\hline $\mathrm{Ca}^{2+}\left(\mathrm{cmol}_{\mathrm{c}} \mathrm{dm}^{-3}\right)$ & 0,60 & 0,80 & 5,40 & 1,10 & 1,60 & 1,90 & 1,80 & 2,00 & 6,10 & 12,20 & 11,00 & 29,10 \\
\hline $\mathrm{Mg}^{2+}\left(\mathrm{cmol}_{\mathrm{c}} \mathrm{dm}^{-3}\right)$ & 0,40 & 0,60 & 1,80 & 1,30 & 1,15 & 0,80 & 0,90 & 1,10 & 4,00 & 5,60 & 4,00 & 10,40 \\
\hline $\mathrm{Na}^{+}\left(\mathrm{cmol}_{\mathrm{c}} \mathrm{dm}^{-3}\right)$ & 0,02 & 0,05 & 0,04 & 0,04 & 0,11 & 0,04 & 0,02 & 0,25 & 0,10 & 0,30 & 0,09 & 2,19 \\
\hline $\mathrm{Al}^{3+}\left(\mathrm{cmol}_{\mathrm{c}} \mathrm{dm}^{-3}\right)$ & 0,11 & 0,96 & 0,00 & 0,32 & 0,00 & 0,32 & 0,00 & 0,05 & 0,0 & 0,00 & 0,00 & 0,00 \\
\hline$(\mathrm{H}+\mathrm{Al})\left(\mathrm{cmol}_{\mathrm{c}} \mathrm{dm}^{-3}\right)$ & 1,68 & 5,67 & 2,75 & 5,50 & 2,14 & 4,28 & 1,07 & 2,29 & 2,90 & 1,53 & 1,22 & 0,76 \\
\hline CTC efetiva $\left(\mathrm{cmol}_{\mathrm{c}} \mathrm{dm}^{-3}\right)$ & 1,17 & 2,49 & 7,63 & 3,00 & 3,04 & 3,24 & 2,90 & 3,59 & 10,89 & 18,31 & 15,69 & 42,37 \\
\hline CTC $\left(\mathrm{cmol}_{\mathrm{c}} \mathrm{dm}^{-3}\right)$ & 2,74 & 7,20 & 10,38 & 8,18 & 5,18 & 7,20 & 3,97 & 5,83 & 13,74 & 19,84 & 16,91 & 43,13 \\
\hline Areia grossa (dag kg-1) & 52 & 59 & 30 & 53 & 45 & 21 & 61 & 43 & 46 & 33 & 16 & 13 \\
\hline Areia fina $\left(\right.$ dag $\left.\mathrm{kg}^{-1}\right)$ & 36 & 25 & 28 & 13 & 20 & 28 & 28 & 38 & 21 & 31 & 29 & 9 \\
\hline Silte $($ dag kg-1) & 3 & 4 & 24 & 11 & 6 & 13 & 8 & 11 & 19 & 17 & 35 & 35 \\
\hline Argila (dag kg-1) & 9 & 12 & 18 & 23 & 29 & 38 & 3 & 8 & 14 & 19 & 20 & 43 \\
\hline Dens. do solo $\left(\mathrm{g} \mathrm{cm}^{-3}\right)$ & 1,47 & 1,48 & 1,44 & 1,36 & 1,35 & 1,28 & 1,67 & 1,54 & 1,42 & 1,43 & 1,34 & 1,29 \\
\hline Dens. de partículas $\left(\mathrm{g} \mathrm{cm}^{-3}\right)$ & 2,80 & 2,79 & 2,65 & 2,60 & 2,67 & 2,80 & 2,96 & 2,82 & 2,73 & 2,78 & 2,69 & 2,65 \\
\hline $\mathrm{Ki}\left(\mathrm{SiO}_{2} / \mathrm{Al}_{2} \mathrm{O}_{3}\right)^{(4)}$ & 1,72 & 1,92 & 2,11 & 2,46 & 2,16 & 2,25 & 2,17 & 2,93 & 3,42 & 4,21 & 3,20 & 4,52 \\
\hline Silte/Argila & 0,33 & 0,33 & 1,33 & 0,47 & 0,20 & 0,34 & 2,66 & 1,37 & 1,35 & 0,89 & 1,75 & 0,81 \\
\hline $\begin{array}{l}\text { Minerais predominantes } \\
\text { na fração argila }{ }^{(5)}\end{array}$ & $\begin{array}{c}\mathrm{Ct}, \mathrm{Gb} \\
\mathrm{Gt}\end{array}$ & $\mathrm{Ct}, \mathrm{Gt}$ & $\begin{array}{l}\mathrm{Ct}, \mathrm{Gt}, \\
\mathrm{Mi},(2: 1)\end{array}$ & $\mathrm{Ct}, \mathrm{Gt}$ & $\mathrm{Ct}, \mathrm{Gt}$ & $\begin{array}{l}\mathrm{Ct}, \mathrm{Gt}, \\
\mathrm{Mi}, \mathrm{Hm}\end{array}$ & $\begin{array}{l}\mathrm{Ct}, \mathrm{Mi} \\
\mathrm{Qz}(2: 1)\end{array}$ & $\begin{array}{l}\mathrm{Mi}, \mathrm{Ct} \\
(2: 1)\end{array}$ & $\begin{array}{l}\mathrm{Ct}, \mathrm{Mi} \\
(2: 1), \mathrm{Fp}\end{array}$ & $\begin{array}{l}(2: 1), \mathrm{Mi} \\
\quad \mathrm{Ct}, \mathrm{Gt}\end{array}$ & $\begin{array}{l}\text { Mi, Ct } \\
(2: 1)\end{array}$ & $\begin{array}{c}(2: 1), \mathrm{Qz} \\
\mathrm{Mi}\end{array}$ \\
\hline Município de Coleta & Jacumã & $\begin{array}{l}\text { Maman- } \\
\text { guape }\end{array}$ & $\begin{array}{l}\text { Mari- } \\
\text { zópolis }\end{array}$ & Areia & Cuité & $\begin{array}{l}\text { Alagoa } \\
\text { Grande }\end{array}$ & $\begin{array}{l}\text { Espe- } \\
\text { rança }\end{array}$ & Pocinhos & $\begin{array}{c}\text { São Miguel } \\
\text { de Taipu }\end{array}$ & Cuité & Sousa & Sousa \\
\hline
\end{tabular}

(1) Análises realizadas conforme métodos apresentados em Embrapa (1997). ${ }^{(2)}$ PA: Argissolo Amarelo; PAC: Argissolo Acinzentado; PVe: Argissolo Vermelho eutrófico; PVA: Argissolo Vermelho-Amarelo; LA: Latossolo Amarelo; PVd: Argissolo Vermelho distrófico; RR: Neossolo Regolítico; RL: Neossolo Litólico; TX: Luvissolo Háplico; SX: Planossolo Háplico; RY: Neossolo Flúvico; VX: Vertissolo Háplico. ${ }^{(3)}$ Fonte: Medeiros (2007). ${ }^{(4)}$ Fonte: Brasil (1972). ${ }^{(5)} \mathrm{Ct}$ : caulinita; Gb: gibbsita; Gt: goethita; Mi: mica; (2:1): mineral 2:1; Hm: hematita; Qz: quartzo; Fp: feldspato. Os minerais estão citados na ordem de sua predominância no solo.

foram aplicados $175 \mathrm{mg} \mathrm{dm}^{-3}$ de $\mathrm{P}$; nos solos PVe e RR, $150 \mathrm{mg} \mathrm{dm}^{-3}$ de P; e nos solos PVd e VX a dose de $\mathrm{P}$ foi de $205 \mathrm{mg} \mathrm{dm}^{-3}$. Como no plantio foram aplicados $20 \mathrm{mg} \mathrm{dm}^{-3}$ de $\mathrm{N}$ na forma de $\mathrm{NH}_{4} \mathrm{H}_{2} \mathrm{PO}_{4}$, o restante do $\mathrm{P}$ necessário para completar essas doses foi fornecido no plantio pelo $\mathrm{Ca}\left(\mathrm{H}_{2} \mathrm{PO}_{4}\right)_{2} \cdot \mathrm{H}_{2} \mathrm{O}$ p.a. Após realização da adubação, as amostras dos solos foram novamente acondicionadas nos vasos e umedecidas com quantidade de água destilada correspondente a $50 \%$ da porosidade total do solo original.

Logo em seguida foi feita a semeadura, colocandose seis sementes do milho híbrido 2C577 por vaso. Cinco dias após a emergência, foi feito o primeiro desbaste, deixando-se três plantas por vaso; três dias depois, foi realizado o segundo desbaste, deixando-se duas plantas por vaso. Diariamente, era realizado o controle da umidade do solo dentro de cada vaso, por meio de pesagens, repondo aos vasos a quantidade de água perdida entre uma irrigação e outra.

Trinta dias após a semeadura, foi efetuado o corte da parte aérea das plantas de cada vaso a $1 \mathrm{~cm}$ do solo, que depois foi submetida a uma pré-secagem ao sol dentro da casa de vegetação. As raízes foram retiradas dos vasos, tendo-se o cuidado de retirar o excesso de solo aderido a elas primeiramente com água corrente e depois com água destilada. Após um dia de pré-secagem, o material vegetal (parte aérea + raízes) foi colocado em sacos de papel perfurado e levado para uma estufa de circulação forçada de ar a $70^{\circ} \mathrm{C}$, onde ficou até atingir peso constante. A matéria seca da parte aérea e das raízes foi triturada em moinho tipo Wiley e mineralizada por digestão sulfúrica (Tedesco et al., 1995); e dosado o K nos extratos por fotometria de chama. O K extraído pela planta foi calculado dividindo-se o conteúdo de $\mathrm{K}$ na planta (parte aérea + raízes) pelo volume de solo dentro do vaso.

O delineamento experimental foi o de blocos casualizados com três repetições e 60 tratamentos (12 solos x 5 doses de K), totalizando 180 unidades experimentais. Cada unidade experimental era constituída de um vaso plástico sem dreno contendo $3,0 \mathrm{dm}^{3}$ de solo e duas plantas de milho. Devido à ampla variação de características físicas, químicas e mineralógicas dos solos, o que implicaria em grande variação entre solos dos valores do quadrado médio do resíduo, optou-se por fazer a análise de variância considerando cada solo como um experimento em blocos casualizados com três repetições e cinco tratamentos (cinco doses de K). 
Foram ajustadas equações de regressão linear simples, que estimam os teores de K recuperados pelos extratores e pela planta em função das doses de K aplicadas. Os coeficientes de regressão dessas equações ( $\Delta \mathrm{K}$ recuperado/ $\Delta \mathrm{K}$ aplicado) foram correlacionados com características químicas e físicas dos solos. A eficiência de cada extrator foi avaliada por meio de análise de regressão, na qual o conteúdo de $\mathrm{K}$ na planta foi considerado como variável dependente do teor de $\mathrm{K}$ no solo extraído pelos extratores.

\section{RESULTADOS E DISCUSSÃO}

Comparando os extratores e a planta quanto à capacidade de extração de $\mathrm{K}$ nos solos mais desenvolvidos, é possível estabelecer a seguinte ordem decrescente da quantidade média de K extraído do solo: Mehlich-1 > Mehlich-3 > resina > planta (Quadro 2). Para o grupo de solos menos desenvolvidos, a sequência foi: Mehlich-3 > Mehlich-1 > planta > resina (Quadro 3). Essa inferioridade da resina quanto à quantidade de $\mathrm{K}$ disponível extraído do solo é mais

Quadro 2. Teores de K disponível ${ }^{(1)}$ extraído pelos extratores Mehlich-1, resina de troca iônica e Mehlich-3 e $\mathrm{K}$ extraído pela planta ${ }^{(2)}$, em função de doses de $\mathrm{K}$ adicionadas em solos mais desenvolvidos do Estado da Paraíba

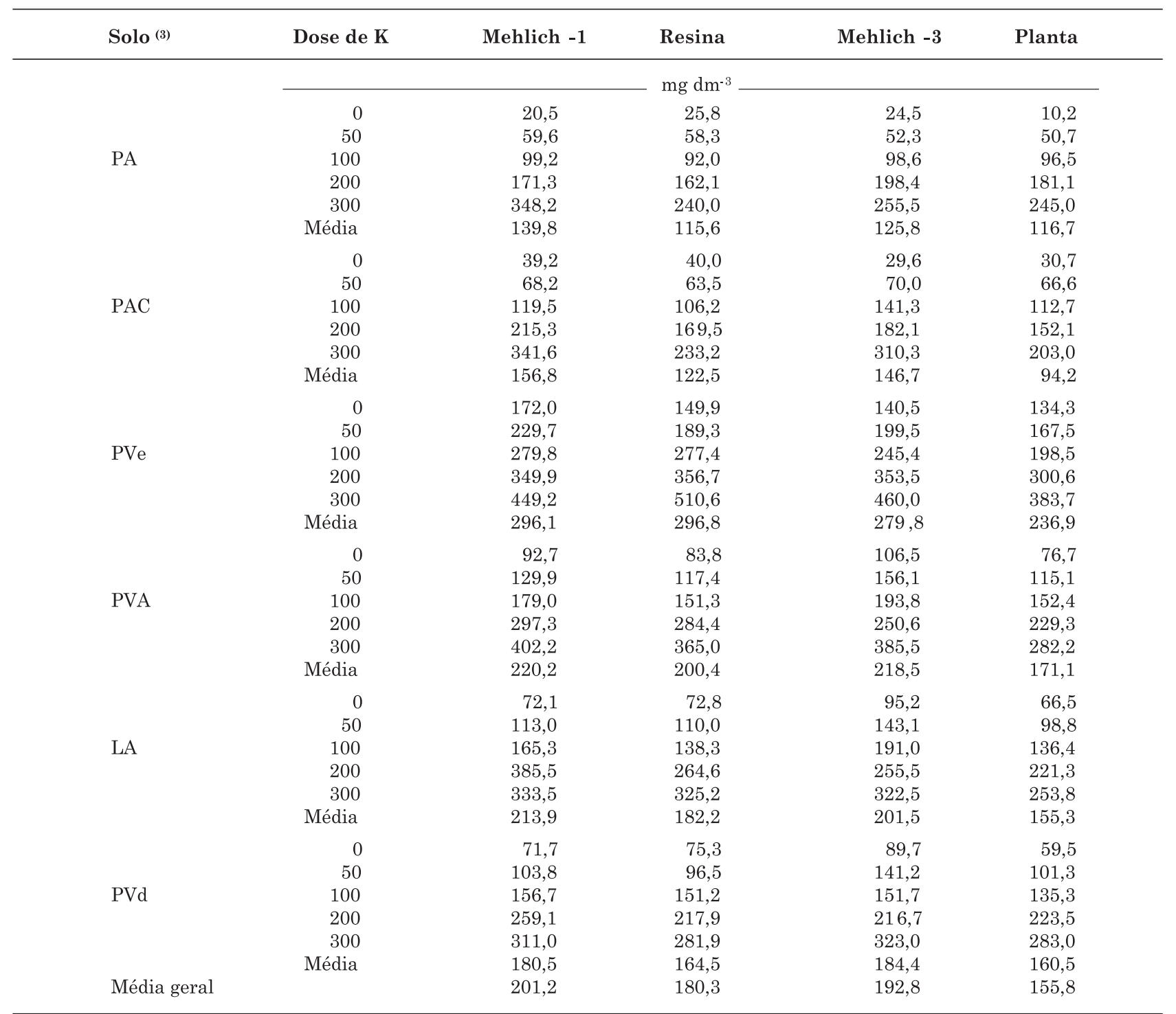

(1) A resina de troca iônica foi utilizada conforme Raij et al. (2001). Para os demais extratores, seguiram-se procedimentos apresentados em Helmke \& Sparks (1996), mas adotando-se a relação solo:solução (m/v) de 1:10 e tempo de agitação de 5 min. ${ }^{(2)} \mathrm{K}$ acumulado em duas plantas de milho (parte aérea + raízes) após 30 dias de cultivo em um vaso contendo 3,0 dm ${ }^{3}$ de solo. (3) PA: Argissolo Amarelo; PAC: Argissolo Acinzentado; PVe: Argissolo Vermelho eutrófico; PVA: Argissolo Vermelho-Amarelo; LA: Latossolo Amarelo; PVd: Argissolo Vermelho distrófico. 


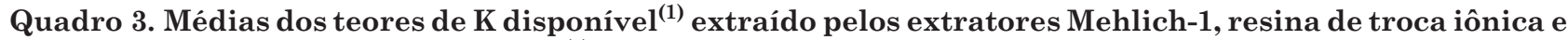
Mehlich-3 e K extraído pela planta ${ }^{(2)}$, em função de doses de K adicionadas em solos menos desenvolvidos do Estado da Paraíba

\begin{tabular}{|c|c|c|c|c|c|}
\hline Solo ${ }^{(3)}$ & Dose de K & Mehlich-1 & Resina & Mehlich-3 & Planta \\
\hline \multirow{7}{*}{$\mathrm{RR}$} & & & $\mathrm{mg} \mathrm{dm} \mathrm{m}^{-3}$ & & \\
\hline & 0 & 76,9 & 78,4 & 98,6 & 54,2 \\
\hline & 50 & 108,3 & 104,7 & 134,7 & 99,0 \\
\hline & 100 & 175,5 & 157,4 & 213,0 & 146,8 \\
\hline & 200 & 302,1 & 224,0 & 278,9 & 209,4 \\
\hline & 300 & 358,3 & 256,4 & 355,9 & 271,1 \\
\hline & Média & 204,2 & 164,2 & 216,2 & 156,1 \\
\hline \multirow[t]{6}{*}{$\mathrm{RL}$} & 0 & 77,8 & 86,6 & 116,4 & 74,5 \\
\hline & 50 & 115,8 & 128,0 & 171,5 & 113,3 \\
\hline & 100 & 139,7 & 146,0 & 207,4 & 144,6 \\
\hline & 200 & 244,0 & 191,6 & 265,0 & 205,7 \\
\hline & 300 & 280,7 & 243,1 & 325,8 & 273,7 \\
\hline & Média & 171,6 & 159,0 & 217,2 & 162,3 \\
\hline \multirow[t]{6}{*}{$\mathrm{TX}$} & 0 & 281,6 & 244,6 & 279,1 & 230,4 \\
\hline & 50 & 304,7 & 256,2 & 298,5 & 261,1 \\
\hline & 100 & 350,8 & 278,7 & 366,4 & 284,8 \\
\hline & 200 & 425,7 & 347,7 & 492,4 & 329,8 \\
\hline & 300 & 500,6 & 431,6 & 569,2 & 363,6 \\
\hline & Média & 372,7 & 311,7 & 401,1 & 294,0 \\
\hline \multirow[t]{6}{*}{$\mathrm{SX}$} & 0 & 83,3 & 51,4 & 101,8 & 60,9 \\
\hline & 50 & 79,1 & 50,5 & 96,4 & 62,2 \\
\hline & 100 & 85,4 & 57,2 & 103,5 & 66,9 \\
\hline & 200 & 97,0 & 61,7 & 134,4 & 80,2 \\
\hline & 300 & 106,5 & 67,6 & 142,0 & 84,3 \\
\hline & Média & 90,2 & 57,7 & 115,6 & 70,9 \\
\hline \multirow[t]{6}{*}{$\mathrm{RY}$} & 0 & 244,0 & 146,2 & 193,3 & 280,3 \\
\hline & 50 & 260,3 & 152,8 & 211,6 & 307,0 \\
\hline & 100 & 287,5 & 166,0 & 229,9 & 321,5 \\
\hline & 200 & 309,3 & 204,0 & 280,2 & 346,0 \\
\hline & 300 & 363,6 & 223,2 & 350,3 & 372,4 \\
\hline & Média & 293,0 & 178,4 & 253,1 & 325,4 \\
\hline \multirow[t]{6}{*}{ VX } & 0 & 297,7 & 179,1 & 479,6 & 217,9 \\
\hline & 50 & 313,4 & 157,3 & 516,3 & 209,5 \\
\hline & 100 & 334,4 & 178,2 & 529,5 & 232,1 \\
\hline & 200 & 381,5 & 172,4 & 562,7 & 234,3 \\
\hline & 300 & 423,3 & 190,9 & 614,1 & 219,7 \\
\hline & Média & 350,1 & 175,6 & 540,5 & 222,7 \\
\hline \multicolumn{2}{|c|}{ Média geral } & 247,0 & 174,4 & 290,6 & 205,2 \\
\hline
\end{tabular}

(1) A resina de troca iônica foi utilizada conforme Raij et al. (2001). Para os demais extratores, seguiram-se procedimentos apresentados em Helmke \& Sparks (1996), mas adotando-se a relação solo:solução (m/v) de 1:10 e tempo de agitação de 5 min. ${ }^{(2)} \mathrm{K}$ acumulado em duas plantas de milho (parte aérea + raízes) após 30 dias de cultivo em um vaso contendo 3,0 dm ${ }^{3}$ de solo. ${ }^{(3)}$ RR: Neossolo Regolítico; RL: Neossolo Litólico; TX: Luvissolo Háplico; SX: Planossolo Háplico; RY: Neossolo Flúvico; VX: Vertissolo Háplico.

evidente nos solos SX, RY e VX, que são os solos menos desenvolvidos que apresentam maior teor de argila, maior proporção de minerais do tipo 2:1 e, consequentemente, maior reserva de $\mathrm{K}$ não trocável (Quadro 1). Nos solos mais desenvolvidos, observa-se que as diferenças entre os teores médios de K extraídos pelos extratores foram menores que as verificadas nos menos desenvolvidos (Quadros 2 e 3).

Para todos os extratores, não houve muita variação entre solos da taxa de recuperação do $\mathrm{K}$ aplicado aos solos mais desenvolvidos (Quadro 4), enquanto no grupo de solos menos desenvolvidos essa variação foi considerável (Quadro 5). Por exemplo, para o extrator Mehlich-1, a taxa de recuperação do K aplicado variou de 84 (PVd) a 106 \% (PVA) nos solos mais desenvolvidos
(Quadro 4) e de 9 (SX) a $100 \%$ (RR) nos menos desenvolvidos (Quadro 5). No caso da resina de troca iônica, esses valores variaram de 66 (PAC) a $119 \%$ (PVe) dentro do grupo de solos mais desenvolvidos (Quadro 4) e de 0 (VX) a 64 \% (TX) no grupo dos menos desenvolvidos (Quadro 5). No solo VX - solo menos desenvolvido mais argiloso e com maior reserva de $\mathrm{K}$ trocável (Quadro 1) - não houve efeito de doses de K na quantidade de K extraída do solo pela resina e pela planta (Quadro 5). A análise de correlação considerando todos os solos $(n=12)$ mostrou que as taxas de recuperação de $\mathrm{K}$ pelos extratores e pela planta correlacionaram-se significativa e negativamente com a CTC efetiva e com o índice Ki (Quadro 6), indicando que os extratores e a planta recuperam menor proporção da dose de $\mathrm{K}$ aplicada em solos menos 
Quadro 4. Equações de regressão linear simples que estimam os teores de K disponível do solo (y, em

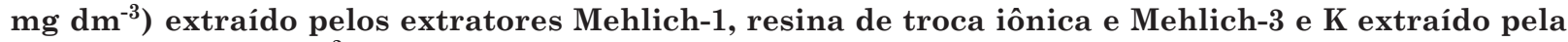
planta (y, em mg dm${ }^{-3}$ ), em solos mais desenvolvidos do Estado da Paraíba, como variável dependente de doses de $\mathrm{K}\left(\mathrm{x}, \mathrm{em} \mathrm{mg} \mathrm{dm}^{-3}\right)$ aplicadas aos solos

\begin{tabular}{|c|c|c|c|}
\hline Solo ${ }^{(1)}$ & Ext rator de $K$ disponível & Equação ${ }^{(2)}$ & $\mathbf{R}^{2}$ \\
\hline $\mathrm{PA}$ & $\begin{array}{l}\text { Mehlich-1 } \\
\text { Resina de troca iônica } \\
\text { Mehlich-3 } \\
\text { K extraído pela planta }\end{array}$ & $\begin{array}{l}\hat{y}=3,54+1,0478^{* *} x \\
\hat{y}=22,92+0,7132^{* *} x \\
\hat{y}=20,48+0,8104^{* *} x \\
\hat{y}=13,51+0,7940^{* *} x\end{array}$ & $\begin{array}{l}0,95 \\
0,99 \\
0,99 \\
0,99\end{array}$ \\
\hline PAC & $\begin{array}{l}\text { Mehlich-1 } \\
\text { Resina de troca iônica } \\
\text { Mehlich-3 } \\
\text { K extraído pela planta }\end{array}$ & $\begin{array}{l}\hat{y}=24,52+1,0172^{* *} x \\
\hat{y}=37,25+0,6557^{* *} x \\
\hat{y}=30,56+0,8932^{* *} x \\
\hat{y}=40,27+0,5597^{* *} x\end{array}$ & $\begin{array}{l}0,99 \\
0,99 \\
0,97 \\
0,98\end{array}$ \\
\hline $\mathrm{PVe}$ & $\begin{array}{l}\text { Mehlich-1 } \\
\text { Resina de troca iônica } \\
\text { Mehlich-3 } \\
\text { K extraído pela planta }\end{array}$ & $\begin{array}{l}\hat{y}=180,19+0,8917^{* *} x \\
\hat{y}=142,51+1,1866^{* *} x \\
\hat{y}=142,27+1,0579^{* *} x \\
\hat{y}=126,09+0,8526^{* * x}\end{array}$ & $\begin{array}{l}0,99 \\
0,98 \\
0,99 \\
0,99\end{array}$ \\
\hline PVA & $\begin{array}{l}\text { Mehlich-1 } \\
\text { Resina de troca iônica } \\
\text { Mehlich-3 } \\
\text { K extraído pela planta }\end{array}$ & $\begin{array}{l}\hat{y}=82,68+1,0580^{* *} x \\
\hat{y}=72,32+0,9851^{* *} x \\
\hat{y}=104,32+0,8782^{* *} x \\
\hat{y}=78,89+0,6982^{* *} x\end{array}$ & $\begin{array}{l}0,99 \\
0,98 \\
0,97 \\
0,99\end{array}$ \\
\hline LA & $\begin{array}{l}\text { Mehlich-1 } \\
\text { Resina de troca iônica } \\
\text { Mehlich-3 } \\
\text { K extraído pela planta }\end{array}$ & $\begin{array}{l}\hat{y}=78,71+1,0397^{* *} x \\
\hat{y}=66,98+0,8860^{* *} x \\
\hat{y}=104,72+0,7443^{* *} x \\
\hat{y}=70,19+0,6550^{* * x} x\end{array}$ & $\begin{array}{l}0,82 \\
0,98 \\
0,99 \\
0,98\end{array}$ \\
\hline PVd & $\begin{array}{l}\text { Mehlich-1 } \\
\text { Resina de troca iônica } \\
\text { Mehlich-3 } \\
\text { K extraído pela planta }\end{array}$ & $\begin{array}{l}\hat{y}=71,35+0,8392^{* *} x \\
\hat{y}=72,38+0,7090^{* *} x \\
\hat{y}=89,03+0,7340^{* *} x \\
\hat{y}=62,24+0,7560^{* *} x\end{array}$ & $\begin{array}{l}0,98 \\
0,99 \\
0,97 \\
0,99\end{array}$ \\
\hline
\end{tabular}

(1) PA: Argissolo Amarelo; PAC: Argissolo Acinzentado; PVe: Argissolo Vermelho eutrófico; PVA: Argissolo Vermelho-Amarelo; LA: Latossolo Amarelo; PVd: Argissolo Vermelho distrófico. ${ }^{(2)} \mathrm{O}$ coeficiente angular dessas equações é a taxa de recuperação, pelo extrator ou pela planta, da dose de $\mathrm{K}$ aplicada $\left(\Delta \mathrm{K}\right.$ recuperado/ $\Delta \mathrm{K}$ aplicado). ${ }^{* *}$ : significativo a $1 \%$ pelo teste $\mathrm{t}$.

desenvolvidos, que apresentam valores de CTC efetiva e índice Ki elevados, provavelmente pela maior fixação de $\mathrm{K}$ nesses solos.

Mehlich-1, resina e Mehlich-3 geralmente são considerados extratores do K trocável do solo, mas no presente trabalho o K trocável do solo será considerado aquele extraído pelo acetato de amônio $1 \mathrm{~mol} \mathrm{~L}^{-1}$ a pH 7,0 (Helmke \& Sparks, 1996). Os outros três extratores foram considerados como extratores do K disponível. Análises de correlação indicaram correlação significativa e positiva entre os teores de $\mathrm{K}$ disponível extraído pelos extratores Mehlich-1 $\left(\mathrm{r}=0,97^{* *}\right)$, resina $\left(r=0,98^{* *}\right)$ e Mehlich-3 $\left(r=0,97^{* *}\right)$ e os teores de K trocável, dentro do grupo de solos mais desenvolvidos (Quadro 7). Esses resultados estão de acordo com os obtidos em solos brasileiros por Andrade et al. (1978), Prezotti \& Defelipo (1987), Chaves \& Dias (1996) e Valladares et al. (2001). No grupo de solos menos desenvolvidos o comportamento foi semelhante, com exceção da resina, que apresentou baixo valor do coeficiente de correlação, apesar de significativo, com o K trocável $\left(r=0,66^{* *}\right)$. Nos solos menos desenvolvidos, a resina de troca iônica extraiu apenas uma fração do K trocável inversamente proporcional ao teor de argila do solo. Para a dose zero de K, no solo menos desenvolvido e mais arenoso (RR), a resina extraiu $94 \%$ do K trocável, enquanto no menos desenvolvido e mais argiloso (VX) ela só extraiu 27 \% do K trocável (Quadros 1 e 3). Ao contrário dos solos mais desenvolvidos, nos quais os teores de K trocável e não trocável são baixos e, portanto, o $\mathrm{K}$ solúvel em $\mathrm{CaCl}_{2}$ e em água destilada representa grande parte do $\mathrm{K}$ presente no solo (Quadro 1), nos solos menos desenvolvidos os teores de $\mathrm{K}$ solúvel em $\mathrm{CaCl}_{2}$ ou em água não mostraram boa correlação com os teores de $\mathrm{K}$ trocável e com o K extraído pela planta (Quadro 7). Quanto ao K não trocável, essa forma de K do solo não apresentou boa correlação com nenhuma das outras formas de $\mathrm{K}$ do solo nem com nenhuma forma de $\mathrm{K}$ disponível (Quadro 7).

Essas correlações significativas (Quadro 7) mostram a possibilidade de se usar, em solos do Estado da Paraíba, qualquer um dos extratores testados para estimar o K trocável, com exceção da resina de troca iônica para solos argilosos e menos desenvolvidos, que extraiu pequena quantidade de $\mathrm{K}$ nesses solos. $\mathrm{Na}$ 
Quadro 5. Equações de regressão linear simples que estimam os teores de K disponível do solo (y, em

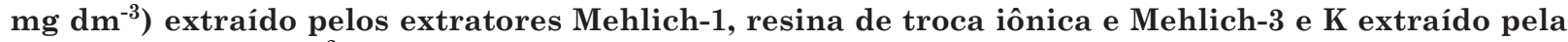
planta (y, em mg dm ${ }^{-3}$ ), em solos menos desenvolvidos do Estado da Paraíba, como variável dependente de doses de $\mathrm{K}\left(\mathrm{x}, \mathrm{em} \mathrm{mg} \mathrm{dm}^{-3}\right)$ aplicadas aos solos

\begin{tabular}{|c|c|c|c|}
\hline Solo ${ }^{(1)}$ & Extrator de $\mathrm{K}$ disponível & Equação (2) & $\mathbf{R}^{2}$ \\
\hline $\mathrm{RR}$ & $\begin{array}{l}\text { Mehlich-1 } \\
\text { Resina de troca iônica } \\
\text { Mehlich-3 } \\
\text { K extraído pela planta }\end{array}$ & $\begin{array}{l}\hat{y}=73,94+1,0023^{* *} \mathrm{x} \\
\hat{y}=83,54+0,6204^{* *} \mathrm{x} \\
\hat{y}=104,08+0,8627^{* *} \mathrm{x} \\
\hat{y}=63,35+0,7136^{* *} \mathrm{x}\end{array}$ & $\begin{array}{l}0,97 \\
0,96 \\
0,98 \\
0,99\end{array}$ \\
\hline RL & $\begin{array}{l}\text { Mehlich-1 } \\
\text { Resina de troca iônica } \\
\text { Mehlich-3 } \\
\text { K extraído pela planta }\end{array}$ & $\begin{array}{l}\hat{y}=79,16+0,7108^{* *} x \\
\hat{y}=94,34+0,4976^{* *} x \\
\hat{y}=130,11+0,6701^{* *} x \\
\hat{y}=77,54+0,6524^{* * x} x\end{array}$ & $\begin{array}{l}0,97 \\
0,98 \\
0,98 \\
0,99\end{array}$ \\
\hline $\mathrm{TX}$ & $\begin{array}{l}\text { Mehlich-1 } \\
\text { Resina de troca iônica } \\
\text { Mehlich-3 } \\
\text { K extraído pela planta }\end{array}$ & $\begin{array}{l}\hat{y}=275,43+0,7480^{* *} x \\
\hat{y}=228,70+0,6388^{* *} x \\
\hat{y}=266,51+1,0356^{* *} x \\
\hat{y}=236,79+0,4397^{* *} x\end{array}$ & $\begin{array}{l}0,99 \\
0,97 \\
0,98 \\
0,99\end{array}$ \\
\hline sX & $\begin{array}{l}\text { Mehlich-1 } \\
\text { Resina } \\
\text { Mehlich-3 } \\
\text { K extraído pela planta }\end{array}$ & $\begin{array}{l}\hat{y}=78,63+0,0893^{* *} \mathrm{x} \\
\hat{y}=50,08+0,0584^{* *} \mathrm{x} \\
\hat{\mathrm{y}}=94,35+0,1635^{* *} \mathrm{x} \\
\hat{\mathrm{y}}=59,58+0,0871^{* x} \mathrm{x}\end{array}$ & $\begin{array}{l}0,91 \\
0,95 \\
0,88 \\
0,96\end{array}$ \\
\hline RY & $\begin{array}{l}\text { Mehlich-1 } \\
\text { Resina de troca iônica } \\
\text { Mehlich-3 } \\
\text { K extraído pela planta }\end{array}$ & $\begin{array}{l}\hat{y}=242,99+0,3843^{* *} \mathrm{x} \\
\hat{y}=142,54+0,2762^{* * *} x \\
\hat{y}=185,32+0,5210^{* *} x \\
\hat{y}=287,58+0,2911^{* *} x\end{array}$ & $\begin{array}{l}0,97 \\
0,98 \\
0,98 \\
0,98\end{array}$ \\
\hline vX & $\begin{array}{l}\text { Mehlich-1 } \\
\text { Resina de troca iônica } \\
\text { Mehlich-3 } \\
\text { K extraído pela planta }\end{array}$ & $\begin{array}{l}\hat{y}=294,34+0,4286^{* *} \mathrm{x} \\
\hat{\mathrm{y}}=\bar{y}=175,6 \\
\hat{\mathrm{y}}=486,12+0,4180^{* *} \mathrm{x} \\
\hat{\mathrm{y}}=\bar{y}=222,7\end{array}$ & $\begin{array}{c}0,99 \\
-\overline{98} \\
0,98\end{array}$ \\
\hline
\end{tabular}

(1) RR: Neossolo Regolítico; RL: Neossolo Litólico; TX: Luvissolo Háplico; SX: Planossolo Háplico; RY: Neossolo Flúvico; VX: Vertissolo Háplico. ${ }^{(2)} \mathrm{O}$ coeficiente angular dessas equações é a taxa de recuperação, pelo extrator ou pela planta, da dose de $\mathrm{K}$ aplicada $\left(\Delta \mathrm{K}\right.$ recuperado/ $\Delta \mathrm{K}$ aplicado). ${ }^{*} \mathrm{e}^{* *}$ : significativo a 5 e a $1 \%$ pelo teste $\mathrm{t}$.

Quadro 6. Coeficientes de correlação linear simples entre as declividades das equações de regressão linear simples ${ }^{(1)}$ que estimam os teores de K disponível pelos extratores Mehlich-1, resina de troca iônica, Mehlich-3 e K extraído pela planta, como variável dependente de doses de $\mathrm{K}$ aplicadas, e características químicas e físicas dos solos mais e menos desenvolvidos do Estado da Paraíba

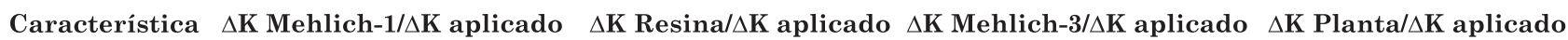

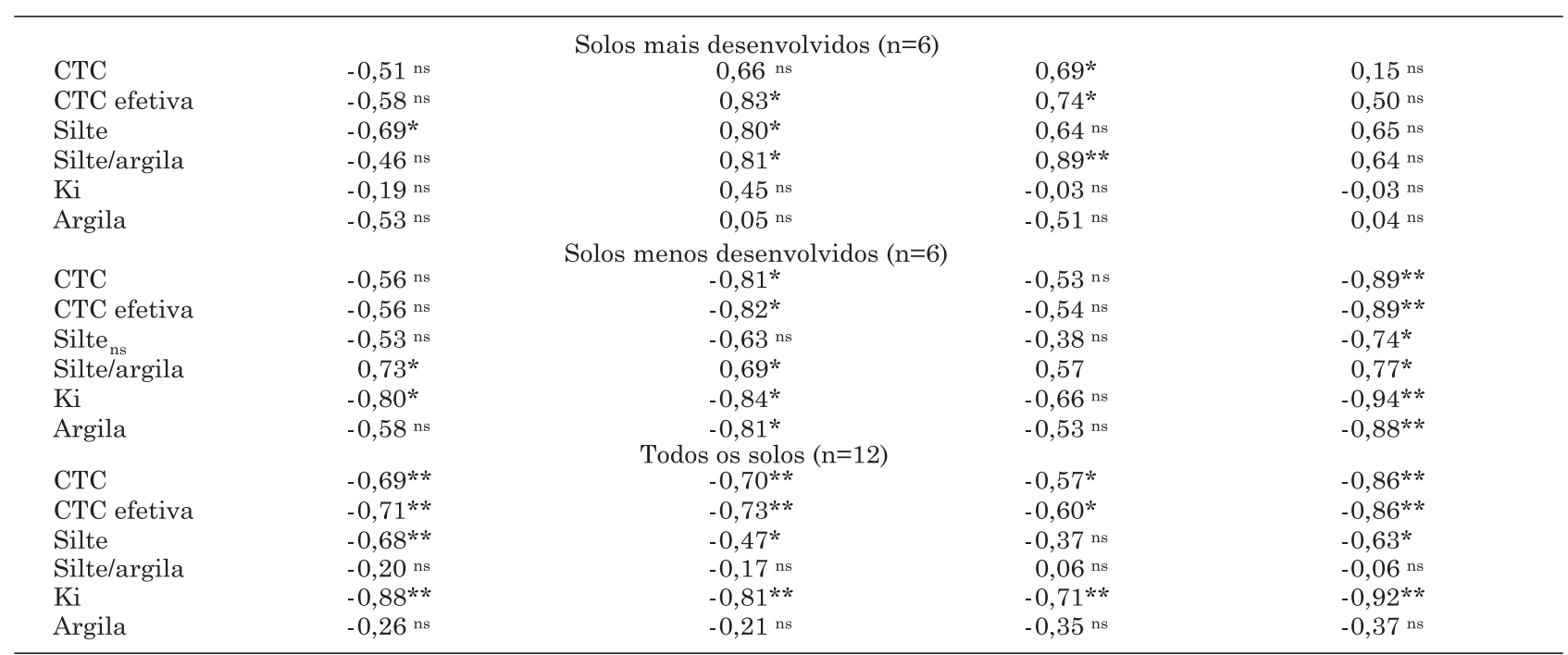

(1) Equações apresentadas nos quadros 4 e $5 .{ }^{*},{ }^{* *}$ e ns: significativo a 5, $1 \%$ e não significativo, respectivamente. 
Quadro 7. Coeficientes de correlação linear simples entre os teores de K extraídos do solo pela planta e os teores de $\mathrm{K}$ não trocável, $\mathrm{K}$ trocável, $\mathrm{K}$ solúvel em $\mathrm{CaCl}_{2}$ e em água e $\mathrm{K}$ disponível pelos extratores Mehlich-1, resina de troca iônica e Mehlich-3, em solos mais e menos desenvolvidos do Estado da Paraíba $^{(1)}$

\begin{tabular}{|c|c|c|c|c|c|c|c|}
\hline & K não trocável & K trocável & $\mathrm{K} \mathrm{CaCl}_{2}$ & K água & K Mehlich-1 & K resina & K Mehlich-3 \\
\hline \multicolumn{8}{|c|}{ Solos mais desenvolvidos $(n=30)$} \\
\hline K-planta & $0,25^{\mathrm{ns}}$ & $0,98^{* *}$ & $0,96 * *$ & $0,90 * *$ & $0,96 * *$ & $0,98 * *$ & $0,98 * *$ \\
\hline K-Mehlich-3 & $0,24^{\mathrm{ns}}$ & $0,97 * *$ & $0,96 * *$ & $0,91 * *$ & $0,96^{* *}$ & $0,97 * *$ & - \\
\hline K-resina & $0,32^{*}$ & $0,98^{* *}$ & $0,93^{* *}$ & $0,86 * *$ & $0,95^{* *}$ & - & - \\
\hline K-Mehlich-1 & $0,18^{\mathrm{ns}}$ & $0,97 * *$ & $0,97 * *$ & $0,93 * *$ & - & - & - \\
\hline K-água & $-0,12^{\mathrm{ns}}$ & $0,88^{* *}$ & $0,97 * *$ & - & - & - & - \\
\hline $\mathrm{K}-\mathrm{CaCl}_{2}$ & $0,09^{\mathrm{ns}}$ & $0,95^{* *}$ & - & - & - & - & - \\
\hline K trocável & $0,32^{*}$ & - & - & - & - & - & - \\
\hline \multicolumn{8}{|c|}{ Solos menos desenvolvidos $(\mathrm{n}=30)$} \\
\hline $\mathrm{K}$-planta & $-0,09^{\mathrm{ns}}$ & $0,67 * *$ & $0,78^{* *}$ & $0,58 * *$ & $0,88^{* *}$ & $0,82^{* *}$ & $0,63 * *$ \\
\hline K-Mehlich-3 & $-0,17^{\mathrm{ns}}$ & $0,98^{* *}$ & $0,47 * *$ & $0,29 *$ & $0,89 * *$ & $0,69 * *$ & - \\
\hline K-resina & $-0,40 * *$ & $0,66^{* *}$ & $0,86^{* *}$ & $0,78^{* *}$ & $0,87 * *$ & - & - \\
\hline K-Mehlich-1 & $-0,18^{\mathrm{ns}}$ & $0,90 * *$ & $0,76^{* *}$ & $0,57 * *$ & - & - & - \\
\hline K-água & $-0,47 * *$ & $0,21 \mathrm{~ns}$ & $0,93 * *$ & - & - & - & - \\
\hline $\mathrm{K}-\mathrm{CaCl}_{2}$ & $-0,37^{*}$ & $0,43^{* *}$ & - & - & - & - & - \\
\hline K trocável & $-0,09^{n s}$ & - & - & - & - & - & - \\
\hline \multicolumn{8}{|c|}{ Todos os solos $(n=60)$} \\
\hline K-planta & $0,15^{\mathrm{ns}}$ & $0,79^{* *}$ & $0,84^{* *}$ & $0,63^{* *}$ & $0,92^{* *}$ & $0,85^{* *}$ & $0,77^{* *}$ \\
\hline K-Mehlich-3 & $0,17^{\mathrm{ns}}$ & $0,98^{* *}$ & $0,61^{* *}$ & $0,40 * *$ & $0,90 * *$ & $0,72^{* *}$ & - \\
\hline $\mathrm{K}$-resina & $-0,16^{\mathrm{ns}}$ & $0,71^{* *}$ & $0,87^{* *}$ & $0,80 * *$ & $0,89 * *$ & - & - \\
\hline K-Mehlich-1 & $0,06^{\mathrm{ns}}$ & $0,90 * *$ & $0,84^{* *}$ & $0,67 * *$ & - & - & - \\
\hline K-água & $-0,40 * *$ & $0,35^{* *}$ & $0,91^{* *}$ & - & - & - & - \\
\hline $\mathrm{K}-\mathrm{CaCl}_{2}$ & $-0,17^{\mathrm{ns}}$ & $0,59 * *$ & - & - & - & - & - \\
\hline K trocável & $0,20^{*}$ & - & - & - & - & - & - \\
\hline
\end{tabular}

(1) Os dados de $\mathrm{K}$ não trocável, $\mathrm{K}$ trocável, $\mathrm{K}$ - $\mathrm{CaCl}_{2}$ e $\mathrm{K}$-água em função das mesmas doses de $\mathrm{K}$ aplicadas aos mesmos solos são apresentados em Medeiros (2007).

escolha de um dos extratores para uso nas análises de rotina visando à recomendação de adubação, outras variáveis deverão ser consideradas, como a correlação entre o extrator e a planta, o custo, o tempo e a laboriosidade para realização das análises, além do grau de impacto ambiental provocado pelo descarte das soluções provenientes da realização dessas análises.

Os dados de produção de matéria seca e de teor de $\mathrm{K}$ na planta em função de doses de $\mathrm{K}$ aplicadas aos solos (Quadro 8) indicam claramente que na maioria deles o crescimento do milho não aumentou com o incremento da dose de $\mathrm{K}$ aplicada, embora em todos os solos o teor de K na matéria seca tenha aumentado (Quadro 8), o que indica consumo de luxo. No entanto, há de se considerar que, nas folhas e colmos de plantas de milho, tanto o acúmulo de matéria seca como a absorção de $\mathrm{K}$ são relativamente lentos no início do crescimento da planta, incrementando a partir dos 30-35 dias (Borges, 2006), de modo que a partir desta fase o milho pode não apresentar mais esse consumo de luxo. Assim mesmo, nos solos PA, PAC, PVd e $R R$, que têm menores teores de $\mathrm{K}$ trocável e $\mathrm{K}$ não trocável (Quadro 1), foi observado efeito significativo de doses de K no crescimento das plantas (Quadro 9).

Foram ajustadas equações de regressão linear simples que estimam os teores de K extraído do solo pela planta em função dos teores de $\mathrm{K}$ disponível extraído do solo pelos extratores Mehlich-1, resina de troca iônica, Mehlich-3 e em função dos teores de K trocável (Quadro 10). Com exceção do solo VX, todos esses extratores mostraram-se eficientes para prever a disponibilidade de $\mathrm{K}$ para as plantas tanto nos solos mais desenvolvidos como nos menos desenvolvidos. $\mathrm{O}$ solo VX foi o menos desenvolvido que apresentou menor produção de matéria seca (Quadro 8) e maior teor de K trocável (Quadro 1). O K aplicado pela adubação pode ter sido fixado no solo e se tornado indisponível para as plantas (Mielniczuk, 1980). Com a adubação potássica, aumenta-se o K na solução e, consequentemente, o K trocável. Nessa situação, quando o solo contém argilomineral 2:1, como o solo VX, há migração de $\mathrm{K}$ na solução ou $\mathrm{K}$ trocável para o espaço nas entrecamadas desses minerais, com a possibilidade de fixação de K (Curi et al., 2005). 
Quadro 8. Produção de matéria seca (MS) e teor de K em plantas de milho (parte aérea + raízes) em função de doses de K aplicadas em solos mais e menos desenvolvidos do Estado da Paraíba

\begin{tabular}{|c|c|c|c|c|c|c|c|}
\hline Solo ${ }^{(1)}$ & Dose & MS & Teor K & Solo $^{(2)}$ & Dose & MS & Teor $\mathrm{K}$ \\
\hline & \multicolumn{3}{|c|}{ Solos mais desenvolvidos } & & \multicolumn{3}{|c|}{ Solos menos desenvolvidos } \\
\hline & $\mathrm{mg} \mathrm{dm}{ }^{-3}$ & $\mathrm{~g} /$ vaso & $\mathrm{g} \mathrm{kg}^{-1}$ & & $\mathrm{mg} \mathrm{dm}{ }^{-3}$ & g/vaso & $\mathrm{g} \mathrm{kg}^{-1}$ \\
\hline \multirow[t]{6}{*}{$\mathrm{PA}$} & 0 & 4,6 & 6,7 & $\mathrm{RR}$ & 0 & 17,1 & 9,5 \\
\hline & 50 & 23,9 & 6,4 & & 50 & 26,0 & 11,4 \\
\hline & 100 & 25,4 & 11,4 & & 100 & 28,5 & 15,5 \\
\hline & 200 & 26,3 & 20,8 & & 200 & 26,3 & 23,9 \\
\hline & 300 & 25,2 & 29,3 & & 300 & 29,2 & 28,0 \\
\hline & Média & 21,1 & 14,9 & & Média & 25,4 & 17,7 \\
\hline \multirow[t]{6}{*}{ PAC } & 0 & 9,5 & 9,7 & $\mathrm{RL}$ & 0 & 28,2 & 7,9 \\
\hline & 50 & 15,7 & 12,9 & & 50 & 29,3 & 11,6 \\
\hline & 100 & 17,6 & 19,9 & & 100 & 31,2 & 13,9 \\
\hline & 200 & 17,0 & 27,1 & & 200 & 30,2 & 20,8 \\
\hline & 300 & 19,9 & 30,8 & & 300 & 28,3 & 29,2 \\
\hline & Média & 15,9 & 20,1 & & Média & 29,4 & 16,7 \\
\hline \multirow[t]{6}{*}{$\mathrm{PVe}$} & 0 & 32,4 & 12,5 & $\mathrm{TX}$ & 0 & 28,8 & 24,3 \\
\hline & 50 & 30,1 & 16,8 & & 50 & 30,2 & 26,0 \\
\hline & 100 & 28,9 & 20,6 & & 100 & 29,3 & 29,3 \\
\hline & 200 & 32,5 & 28,0 & & 200 & 29,2 & 33,9 \\
\hline & 300 & 33,3 & 34,5 & & 300 & 31,4 & 34,7 \\
\hline & Média & 31,4 & 22,5 & & Mélia & 29,8 & 29,6 \\
\hline \multirow[t]{6}{*}{ PVA } & 0 & 27,4 & 8,4 & SX & 0 & 18,8 & 9,7 \\
\hline & 50 & 27,0 & 13,0 & & 50 & 21,3 & 8,8 \\
\hline & 100 & 28,8 & 15,2 & & 100 & 20,8 & 9,7 \\
\hline & 200 & 29,2 & 23,8 & & 200 & 21,1 & 11,4 \\
\hline & 300 & 29,8 & 28,9 & & 300 & 19,9 & 12,6 \\
\hline & Média & 28,4 & 17,9 & & Média & 20,4 & 10,4 \\
\hline \multirow[t]{6}{*}{ LA } & 0 & 25,3 & 8,0 & $\mathrm{RY}$ & 0 & 29,2 & 28,8 \\
\hline & 50 & 26,5 & 11,2 & & 50 & 29,7 & 30,9 \\
\hline & 100 & 28,6 & 14,3 & & 100 & 29,2 & 33,0 \\
\hline & 200 & 28,7 & 23,2 & & 200 & 28,8 & 36,0 \\
\hline & 300 & 27,9 & 27,3 & & 300 & 29,5 & 37,8 \\
\hline & Média & 27,4 & 16,8 & & Média & 29,3 & 33,3 \\
\hline \multirow[t]{6}{*}{$\mathrm{PVd}$} & 0 & 24,5 & 7,3 & VX & 0 & 19,4 & 33,7 \\
\hline & 50 & 27,7 & 11,0 & & 50 & 17,7 & 35,5 \\
\hline & 100 & 30,5 & 13,4 & & 100 & 19,0 & 36,6 \\
\hline & 200 & 28,9 & 23,3 & & 200 & 18,1 & 38,8 \\
\hline & 300 & 29,7 & 28,7 & & 300 & 17,9 & 36,7 \\
\hline & Média & 28,3 & 16,7 & & Média & 18,4 & 36,3 \\
\hline \multicolumn{2}{|c|}{ Média Geral } & 25,4 & 21,8 & Média & & 25,5 & 24,0 \\
\hline
\end{tabular}

(1) PA: Argissolo Amarelo; PAC: Argissolo Acinzentado; PVe: Argissolo Vermelho eutrófico; PVA: Argissolo Vermelho-Amarelo; LA: Latossolo Amarelo; PVd: Argissolo Vermelho distrófico. ${ }^{(2)}$ RR: Neossolo Regolítico; RL: Neossolo Litólico; TX: Luvissolo Háplico; SX: Planossolo Háplico; RY: Neossolo Flúvico; VX: Vertissolo Háplico. 
Quadro 9. Equações de regressão que estimam a produção de matéria seca (y, em g/vaso) e o teor de K (y, em $\mathrm{g} \mathrm{kg}^{-1}$ ) em plantas de milho, em função de doses de $\mathrm{K}$ aplicadas (x, em $\mathrm{mg} \mathrm{dm}^{-3}$ ) em solos mais e menos desenvolvidos do Estado da Paraíba

\begin{tabular}{|c|c|c|c|}
\hline Solo(1) & Característica & Equação & $\mathbf{R}^{2}$ \\
\hline PA & $\begin{array}{l}\text { Matéria seca } \\
\text { Teor de K }\end{array}$ & $\begin{array}{l}\text { Solos mais desenvolvidos } \\
\hat{\mathrm{y}}=4,89+3,446^{* *} \mathrm{x}^{0,5}-0,1325^{* *} \mathrm{x} \\
\hat{\mathrm{y}}=4,37+0,0812^{* *} \mathrm{x}\end{array}$ & $\begin{array}{l}0,99 \\
0,97\end{array}$ \\
\hline PAC & $\begin{array}{l}\text { Matéria seca } \\
\text { Teor de K }\end{array}$ & $\begin{array}{l}\hat{y}=10,88+0,0697^{* *} \mathrm{x}-0,0001^{*} \mathrm{x}^{2} \\
\hat{\mathrm{y}}=10,63+0,0728^{* *} \mathrm{x}\end{array}$ & $\begin{array}{l}0,81 \\
0,96\end{array}$ \\
\hline $\mathrm{PVe}$ & $\begin{array}{l}\text { Matéria seca } \\
\text { Teor de K }\end{array}$ & $\begin{array}{l}\hat{y}=\bar{y}=31,40 \\
\hat{\mathrm{y}}=13,00+0,0730^{* *} \mathrm{x}\end{array}$ & $0, \overline{99}$ \\
\hline PVA & $\begin{array}{l}\text { Matéria seca } \\
\text { Teor de K }\end{array}$ & $\begin{array}{l}\hat{\mathrm{y}}=\bar{y}=28,40 \\
\hat{\mathrm{y}}=8,90+0,0690^{* *} \mathrm{x}\end{array}$ & $0, \overline{99}$ \\
\hline LA & $\begin{array}{l}\text { Matéria seca } \\
\text { Teor de K }\end{array}$ & $\begin{array}{l}\hat{\mathrm{y}}=\bar{y}=27,40 \\
\hat{\mathrm{y}}=8,08+0,0673^{* *} \mathrm{x}\end{array}$ & 0,98 \\
\hline $\mathrm{PVd}$ & $\begin{array}{l}\text { Matéria seca } \\
\text { Teor de K }\end{array}$ & $\begin{array}{l}\hat{\mathrm{y}}=24,41+0,7653^{* *} \mathrm{x}^{0,5}-0,0276^{* *} \mathrm{x} \\
\hat{\mathrm{y}}=7,16+0,0737^{* *} \mathrm{x}\end{array}$ & $\begin{array}{l}0,87 \\
0,99\end{array}$ \\
\hline $\mathrm{RR}$ & $\begin{array}{l}\text { Matéria seca } \\
\text { Teor de K }\end{array}$ & $\begin{array}{l}\text { Solos menos desenvolvidos } \\
\hat{\mathrm{y}}=17,33+1,5605^{* *} \mathrm{x}^{0,5}-0,0543^{* *} \mathrm{x} \\
\hat{\mathrm{y}}=9,08+0,0660^{* *} \mathrm{x}\end{array}$ & $\begin{array}{l}0,92 \\
0,98\end{array}$ \\
\hline $\mathrm{RL}$ & $\begin{array}{l}\text { Matéria seca } \\
\text { Teor de K }\end{array}$ & $\begin{array}{l}\hat{\mathrm{y}}=\bar{y}=29,40 \\
\hat{\mathrm{y}}=7,64+0,0696^{* *} \mathrm{x}\end{array}$ & 0,99 \\
\hline $\mathrm{TX}$ & $\begin{array}{l}\text { Matéria seca } \\
\text { Teor de K }\end{array}$ & $\begin{array}{l}\hat{y}=\bar{y}=29,80 \\
\hat{y}=24,79+0,0373^{* *} \mathrm{x}\end{array}$ & $0, \overline{9} 4$ \\
\hline sX & $\begin{array}{l}\text { Matéria seca } \\
\text { Teor de K }\end{array}$ & $\begin{array}{l}\hat{\mathrm{y}}=\bar{y}=20,40 \\
\hat{\mathrm{y}}=8,91+0,0119^{* *} \mathrm{x}\end{array}$ & $0, \overline{85}$ \\
\hline $\mathrm{RY}$ & $\begin{array}{l}\text { Matéria seca } \\
\text { Teor de K }\end{array}$ & $\begin{array}{l}\hat{\mathrm{y}}=\bar{y}=29,30 \\
\hat{\mathrm{y}}=29,44+0,0299^{* *} \mathrm{x}\end{array}$ & $0, \overline{9}$ \\
\hline vX & $\begin{array}{l}\text { Matéria seca } \\
\text { Teor de K }\end{array}$ & $\begin{array}{l}\hat{\mathrm{y}}=\bar{y}=18,40 \\
\hat{\mathrm{y}}=33,51+0,0480^{* *} \mathrm{x}-0,0001^{* *} \mathrm{x}^{2}\end{array}$ & 0,95 \\
\hline
\end{tabular}

(1) PA: Argissolo Amarelo; PAC: Argissolo Acinzentado; PVe: Argissolo Vermelho eutrófico; PVA: Argissolo Vermelho-Amarelo; LA: Latossolo Amarelo; PVd: Argissolo Vermelho distrófico; RR: Neossolo Regolítico; RL: Neossolo Litólico; TX: Luvissolo Háplico; SX: Planossolo Háplico; RY: Neossolo Flúvico; VX: Vertissolo Háplico. * e **: significativo a 5 e a $1 \%$, respectivamente.

Quadro 10. Equações de regressão linear simples que estimam os teores de K extraídos do solo pela planta $\left(\mathrm{y}, \mathrm{em} \mathrm{mg} \mathrm{dm} \mathrm{dm}^{-3}\right)$ em função dos teores de $\mathrm{K}$ disponível $\left(\mathrm{x}, \mathrm{em} \mathrm{mg} \mathrm{dm}^{-3}\right)$ extraídos do solo pelos extratores

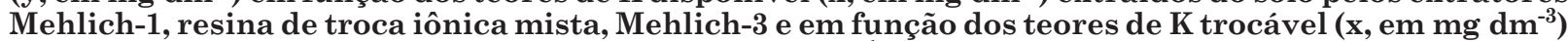
extraídos do solo pelo extrator acetato de amônio $1 \mathrm{~mol} \mathrm{~L}^{-1}$ a pH 7,0, em solos mais e menos desenvolvidos do Estado da Paraíba

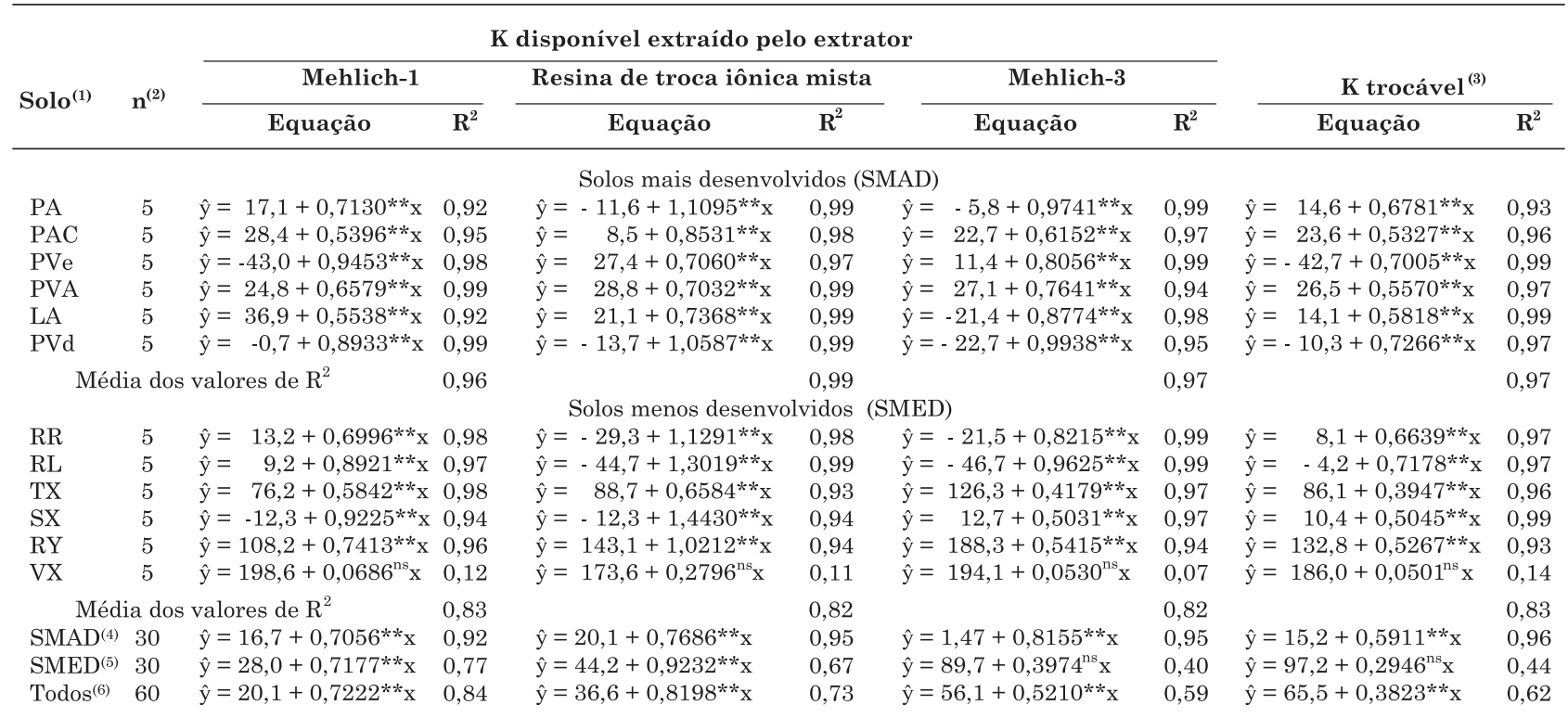

(1)PA: Argissolo Amarelo; PAC: Argissolo Acinzentado; PVe: Argissolo Vermelho eutrófico; PVA: Argissolo Vermelho-Amarelo; LA: Latossolo Amarelo; PVd: Argissolo Vermelho distrófico; RR: Neossolo Regolítico; RL: Neossolo Litólico; TX: Luvissolo Háplico; SX: Planossolo Háplico; RY: Neossolo Flúvico; VX: Vertissolo Háplico. ${ }^{(2)}$ Número de pares de dados utilizados para ajustar o modelo de regressão. ${ }^{(3)}$ Fonte: Os dados de $\mathrm{K}$ trocável em função das mesmas doses de $\mathrm{K}$ aplicadas aos mesmos solos são apresentados em Medeiros (2007). ${ }^{(4)}$ SMAD: solos mais desenvolvidos. ${ }^{(5)}$ SMED: solos menos desenvolvidos. ${ }^{(6)}$ Todos os solos. 


\section{CONCLUSÕES}

1. Os extratores Mehlich-1, Mehlich-3 e resina de troca iônica extraíram teores semelhantes de K nos solos mais desenvolvidos. No grupo dos menos desenvolvidos, os extratores Mehlich-1 e Mehlich-3 extraíram teores semelhantes de K, mas bem maiores que os extraídos pela resina de troca iônica, especialmente naqueles com maior teor de argila e maior proporção de minerais do tipo 2:1.

2. Ao contrário dos extratores Mehlich-1 e Mehlich-3, nos solos menos desenvolvidos, a resina de troca iônica mista não apresentou boa correlação com o teor de K trocável. Nesse grupo de solos, o extrator Mehlich-1 foi o que mostrou melhor correlação com a planta.

3. Na maioria dos solos a produção de matéria seca da planta não aumentou com o incremento das doses de K, mas em todos eles houve aumento do teor de K na planta em resposta à adubação potássica.

\section{LITERATURA CITADA}

ALVAREZ V., V.H.; NOVAIS, R.F.; DIAS, L.E. \& OLIVEIRA J.A. Determinação e uso do fósforo remanescente. B. Inf. Soc. Bras. Ci. Solo, 25:27-32, 2000.

ALVAREZ V., V.H. Correlação e calibração de métodos de análise de solo. In: ALVAREZ V., V.H.; FONTES, L.E.F. \& FONTES, M.P.F. O solo nos grandes domínios morfoclimáticos do Brasil e o desenvolvimento sustentado. Viçosa, MG, SBCS/UFV/DPS, 1996. p.615-646.

ANDRADE, F.P.; DEFELIPPO, B.V.; BRAGA, J.M. \& ALVAREZ V., V.H. Teste de extratores para potássio em quatro solos da região pré-amazônica maranhense. R. Bras. Ci. Solo, 2:200-204, 1978.

BORGES, I.D. Marcha de absorção de nutrientes e acúmulo de matéria seca em milho. Lavras, MG, Universidade Federal de Lavras, 2006. 115p. (Tese de Doutorado).

BRASIL. Ministério da Agricultura. Escritório de pesquisas e experimentação. Equipe de Pedologia e Fertilidade do Solo. I. Levantamento exploratório-reconhecimento de solos do Estado da Paraíba. II. Interpretação para uso agrícola dos solos do Estado da Paraíba. Rio de Janeiro, 1972. 683p. (Boletim Técnico, 15; SUDENE. Série Pedologia, 8)

CASTILHOS, R.M.V. \& MEURER, E.J. Suprimento de potássio de solos do Rio Grande do Sul para arroz irrigado por alagamento. R. Bras. Ci. Solo, 26:977-982, 2002.

CHAVES, L.H.G. \& DIAS, M.M. Formas de potássio em Regossolos do Estado da Paraíba. Pesq. Agropec. Bras. 31:523-528, 1996.

CURI, N.; KAMPF, N. \& MARQUES, J.J. Mineralogia e formas de potássio em solos brasileiros. In: YAMADA, T. \& ROBERTS, T.L., eds. Potássio na agricultura brasileira. Piracicaba, Potafos, 2005. p.71-91

EMPRESA BRASILEIRA DE PESQUISA AGROPECUÁRIA . EMBRAPA. Centro Nacional de Pesquisa do Solo. Manual de métodos de análise de solo. Rio de Janeiro, 1997. 212p.
HELMKE, P.A. \& SPARKS, D.L. Lithium, sodium, rubidium and cesium. In: SPARKS, D.L.; PAGE, A.L.; HELMKE, P.A.; LOEPPERT, R.H.; SOLTANPOUR, P.N.; TABATABAI, M.A.; JOHNSTON, C.T. \& SUMNER, M.E. eds. Methods of soil analisis chemical methods. Madison, SSSA/ASA, 1996. Part 3. p.551-574 (Book Series, 5).

MEDEIROS, J.S. Formas e disponibilidade de potássio para plantas de milho em solos do Estado da Paraíba com graus de intemperismo diferentes. Areia, Universidade Federal da Paraíba, 2007. 50p. (Tese de Mestrado)

MELO, V.F.: BARROS, N.F.; COSTA, L.M.; NOVAIS, R.F. \& FONTES, M.P.F. Forma de potássio e de magnésio em solos do Rio Grande do Sul, e sua relação com o conteúdo na planta e com a produção em plantios de eucalipto. $R$. Bras. Ci. Solo, 19:165-171, 1995.

MIELNICZUK, J. O potássio no solo. Piracicaba, Instituto da Potassa e Fosfato, 1980. 79p. (Boletim Técnico, 2).

NACHTIGALL, G.R. \& VAHL, L.C. Capacidade de suprimento de potássio dos solos da região sul do Rio Grande do Sul. R. Bras. Ci. Solo, 15:37:42, 1991a.

NACHTIGALL, G.R. \& VAHL, L.C. Dinâmica de liberação de potássio dos solos da região sul do Rio Grande do Sul. R. Bras. Ci. Solo, 15:43-47, 1991b.

NACHTIGALL, G.R. \& RAIJ, B.van. Análise e interpretação do potássio no solo. In: YAMADA, T. \& ROBERTS, T.L. Potássio na agricultura brasileira. Piracicaba, POTAFOS. 2005. p.93-118.

OLIVEIRA, F.H.T.; LEAL, J.V.; SANTOS, D.J.; FARIAS, D.R. \& ARRUDA, J.A. Banco de solos representativos do Estado da Paraíba. In: REUNIÃO BRASILEIRA DE MANEJO E CONSERVAĈ̃O DO SOLO E DA ÁGUA. 16., 2006. Anais. Aracaju, SBCS/UFSE, 2006. CD ROM.

PREZOTTI, L.C. \& DEFELIPO, B.V. Formas de potássio em solos do Estado de Minas Gerais. R. Bras. Ci. Solo, 11:109$114,1987$.

RAIJ, B.van. Fertilidade do solo e adubação. Piracicaba, Ceres/ POTAFOS, 1991. 343p.

RAIJ, B.van; ANDRADE, J.C.; CANTARELLA, H. \& QUAGGIO, J.A. Análise química para avaliação da fertilidade de solos tropicais. Campinas, Instituto Agronômico de Campinas, 2001. 285p.

RIBEIRO, A.C.; GUIMARÃES, P.T.G. \& ALVAREZ V., V.H. Recomendações para o uso de corretivos e fertilizantes em Minas Gerais. Viçosa, MG, CFSEMG, 1999. 359p.

ROSOLEM, C.A.; BESSA, A.M. \& PEREIRA, H.F.M. Dinâmica do potássio no solo e nutrição potássica da soja. Pesq. Agropec. Bras., 28:1045-1054, 1993.

SILVA, F.C.; EIRA, P.A.; BARRETO, W.O.; PÉREZ, D.V. \& SILVA, C.A. Análises químicas para avaliação da fertilidade do solo: Métodos usados na Embrapa Solos. Rio de Janeiro, Embrapa/CNPS, 1998. 40p. (Documento, 3)

TEDESCO, M.J.; GIANELLO, C.; BISSANI, C.A.; BOHNEN, H. \& VOLKWEISS, S.J. Análises de solo, plantas e outros materiais. Porto Alegre, Universidade Federal do Rio Grande do Sul, 1995. 188p. (Boletim Técnico, 5)

VALLADARES, G.S.; PEREIRA, M.G.; SOUZA, J.M.P.F.; PÉREZ, D.V. \& ANJOS, L.H.C. Comparação entre os teores de nutrientes extraídos por três métodos em amostras de solos do Rio de Janeiro. R. Bras. Agroci., 7:137-141, 2001. 